\title{
Application of $\mathrm{Ca}$ isotope systematics in studies of carbonatites
}

\author{
JIAN SUN ${ }^{1}$, XIANGKUN ZHU ${ }^{1}$, NICK BELSHAW ${ }^{2}$, WEI \\ CHEN $^{3}$, ANNA G. DOROSHKEVICH ${ }^{4}$, WENJUAN LUO ${ }^{5}$, \\ WENLEI SONG ${ }^{6,7},{\text { BEIBEI } \mathrm{CHEN}^{8} \text {, ZHIGUO CHENG }}^{9}$, ZHI- \\ HONG LI $^{1}$, YANG WANG ${ }^{9}$, JINDRICH KYNICKY ${ }^{6}$ AND \\ GIDEON HENDERSON ${ }^{2}$ \\ ${ }^{1}$ Institute of Geology, Chinese Academy of Geological Sciences \\ ${ }^{2}$ University of Oxford \\ ${ }^{3}$ China University of Geoscience \\ ${ }^{4}$ Sobolev Institute of Geology and Mineralogy Siberian Branch \\ Russian Academy of Sciences \\ ${ }^{5}$ Institute of Mineral Resources, Chinese Academy of Geological \\ Sciences \\ ${ }^{6}$ BIC Brno, Technology Innovation Transfer Chamber \\ ${ }^{7}$ Department of Geology, Northwest University \\ ${ }^{8}$ Institute of Surface-Earth System Science, School of Earth \\ System Science, Tianjin University \\ ${ }^{9}$ China University of Geosciences, Beijing \\ Presenting Author: sunjiantc@163.com
}

Calcium stable isotopes may provide insights into the nature of source and magmatic processes for mantle-derived igneous rocks, but rare studies have been done on carbonatites, the origin of which remains largely unknown. To determine the $\mathrm{Ca}$ isotope composition of carbonatites, much effort has been spent on methodology and a refined $\mathrm{Ca}(-\mathrm{Sr})$ isotope analytical protocol using SSB-MC-ICPMS method has been developed, with the reliability of the analytical data reinforced by repeating analysis of several samples using DS-TIMS method. Worldwide carbonatite and associated silicate rocks were analyzed for $\delta^{44 / 42} \mathrm{Ca}$. Different from most data previsouly reported, our results show that primary carbonatite and associated silicate rocks are rather homogeneous in $\delta^{44 / 42} \mathrm{Ca}$ values that are comparable to those of basalts, while non-primary carbonatites show detectable $\delta^{44 / 42} \mathrm{Ca}$ variation that are correlated to $\delta^{13} \mathrm{C}$ values. Our finding suggests that $\mathrm{Ca}$ isotopes fractionate during late stages of carbonatite evolution and that carbonatite is sourced from a mantle source without requiring the involvement of recycled carbonates. This means that $\mathrm{Ca}$ isotopes are useful for tracing carbonatite source and evolution. 